\title{
Anatomia da madeira de Sebastiania commersoniana (Baillon) Smith \& Downs (Euphorbiaceae): aspectos funcionais e ecológicos ${ }^{1}$
}

\author{
Nelson Luiz Cosmo ${ }^{2,5}$, Yoshiko Saito Kuniyoshi ${ }^{3}$ e Paulo César Botosso ${ }^{4}$
}

Recebido em 5/10/2009. Aceito em 11/06/2010

\begin{abstract}
RESUMO - (Anatomia da madeira de Sebastiania commersoniana (Baillon) Smith \& Downs (Euphorbiaceae): aspectos funcionais e ecológicos). Sebastiania commersoniana é uma espécie arbórea bastante comum em ambientes aluviais, em diversas condições pedológicas, graças a sua plasticidade e capacidade de tolerar períodos de inundação. Foram amostrados 21 indivíduos adultos dessa espécie, na planície do rio Iguaçu, visando à caracterização anatômica da madeira e sua interpretação em termos funcionais. $S$. commersoniana possui porosidade difusa, vasos solitários e múltiplos de dois a seis, com arranjo radial e placas de perfuração simples. Os vasos são pouco freqüentes (12-16-20/mm²), com diâmetro de $54-88-117 \mu \mathrm{m}$ e elementos de vaso com comprimento 164-602-1025 $\mu \mathrm{m}$. As fibras libriformes têm 656-1222-2050 $\mu \mathrm{m}$ de comprimento, 10-26-42 $\mu \mathrm{m}$ de largura, e paredes delgadas a espessas $(1,0-2,8-5,1 \mu \mathrm{m})$. Fibras gelatinosas são freqüentes. Ocorre parênquima apotraqueal difuso em agregados, e paratraqueal escasso. Os raios, unisseriados, têm 164-805-2787 $\mu \mathrm{m}$ de altura e 12-22-35 $\mu \mathrm{m}$ de largura. Células perfuradas de raio são freqüentes, bem como máculas contendo grãos de amido. Estes também ocorrem no parênquima radial e no axial. A espécie desenvolve lenho de tensão em árvores inclinadas. A maioria dos caracteres observados coincide com descrições disponíveis para o gênero e a família a que a espécie pertence. Algumas características qualitativas são discutidas quanto às suas possíveis funções e implicações para a auto-ecologia da espécie.
\end{abstract}

Palavras-chave: anatomia ecológica, floresta aluvial, floresta ripária, xilema secundário

\begin{abstract}
Wood anatomy of Sebastiania commersoniana (Baillon) Smith \& Downs (Euphorbiaceae): functional and ecological aspects). Sebastiania commersoniana is a very common tree species in alluvial environments with diverse soil conditions due to its plasticity and ability to tolerate periods of flooding. In this study we sampled 21 adult individuals of this species on the Iguaçu River plain, for wood anatomy characterization and interpretation using a functional approach. S. commersoniana has diffuse porous, solitary vessels and multiples of two to six, radially arranged with simple perforation

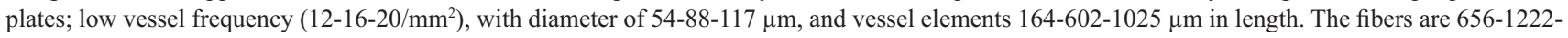
$2050 \mu \mathrm{m}$ in length, 10-26-42 $\mu \mathrm{m}$ wide, the walls are 1.0-2.8-5.1 $\mu \mathrm{m}$ thick. Fibers with a gelatinous layer are common. Apotracheal parenchyma diffusein-aggregates is found, while paratracheal parenchyma is scanty. Rays are uniseriate, 164-805-2787 $\mu \mathrm{m}$ tall and 12-22-35 $\mu \mathrm{m}$ wide. Perforated ray cells are frequent, as well as scar tissue containing starch grains. Starch also occurs in the radial and axial parenchyma. This species develops tension-wood in inclined trees. Most of the features observed coincide with available descriptions of the genus and family to which the species belongs. Some qualitative features are discussed on the base of possible roles and implications for species autoecology.
\end{abstract}

Key words: alluvial forest, ecological anatomy, riparian forest, secondary xylem

\section{Introdução}

Sebastiania commersoniana (Baillon) Smith \& Downs, conhecida como branquilho, ou branquinho, ocorre no Brasil desde o Rio de Janeiro e Minas Gerais até o Rio Grande do Sul (Lorenzi 1992). No Paraná, está presente na Floresta Ombrófila Mista (nas formações montana e aluvial), na Floresta Estacional Semidecidual (aluvial) e nos ecótonos entre essas duas unidades (Isernhagen 2001). A espécie alcança sua maior expressão nas planícies fluviais, principalmente nas formações aluviais da Floresta Ombrófila Mista, onde frequentemente é a espécie dominante (Reitz et al. 1983; Barddal et al. 2003; 2006; Curcio 2006; Curcio et al. 2007).

Nessa condição, Sebastiania commersoniana é capaz de se estabelecer e desenvolver em diversas unidades geomorfológicas e pedológicas (Barddal 2006). Capaz de tolerar períodos relativamente longos de saturação hídrica do solo, a espécie desenvolve respostas adaptativas, fisiológicas e morfoanatômicas a este fator (Kolb et al. 1998; Lobo \& Joly 2000; Barddal 2006), o que explica parcialmente sua freqüente condição de dominância nos ambientes fluviais (Barddal 2006; Curcio et al. 2007).
No entanto, as respostas de indivíduos adultos, crescendo em condições naturais, são escassas na literatura. A análise de aspectos anatômicos nessas condições poderia contribuir para ampliar o conhecimento sobre a plasticidade ecológica da espécie e, ao mesmo tempo, sobre a ecologia das planícies aluviais. $\mathrm{O}$ estudo da estrutura anatômica da madeira normalmente se presta a esse tipo de abordagem, especialmente pela relevância do xilema secundário como tecido de sustentação, armazenamento e transporte hídrico das espécies arbóreas.

Em termos de variações intra-específicas em resposta às condições ambientais, os trabalhos de anatomia ecológica da madeira em geral discutem com mais detalhes aspectos quantitativos. Estudos anatômicos descritivos, por sua vez, normalmente visam uma caracterização geral das espécies. No entanto, em ambas as abordagens as características qualitativas, embora descritas, são discutidas com menos freqüência quanto às suas prováveis funções e implicações ecológicas.

O presente estudo teve como objetivos a caracterização da estrutura anatômica do xilema secundário de Sebastiania commersoniana e a interpretação de algumas características

\footnotetext{
Parte da dissertação de Mestrado do primeiro Autor

2 Universidade Federal do Paraná, Programa de Pós-Graduação em Engenharia Florestal, Curitiba, PR, Brasil

3 Universidade Federal do Paraná, Departamento de Ciências Florestais, Curitiba, PR, Brasil

4 Centro Nacional de Pesquisas Florestais - Embrapa Florestas. Colombo, PR, Brasil

5 Autor para correspondência: ncosmo@gmail.com
} 
qualitativas em termos funcionais, considerando o contexto ecológico em que a espécie ocorre com maior freqüência. Para isso foram amostrados indivíduos adultos desta espécie na planície do rio Iguaçu, no estado do Paraná, em diferentes condições geomorfológicas e pedológicas.

\section{Material e métodos}

Local de coleta - As amostras de madeira de Sebastiania commersoniana foram coletadas em remanescentes da Floresta Ombrófila Mista Aluvial, na planície do rio Iguaçu, nos municípios de Araucária e Lapa, no estado do Paraná. Ambos estão sob clima subtropical úmido mesotérmico - Cfb de Koeppen (Maack 1968).

Foram amostradas 21 árvores em três áreas, sobre superfícies de agrada-

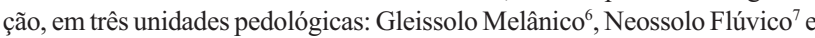
Depósito Psamítico ${ }^{8}$. Estas são descritas detalhadamente em Curcio (2006).

Seleção e coleta de amostras - Em cada uma das áreas amostradas foram selecionados sete indivíduos adultos de S. commersoniana, com troncos relativamente retilíneos e pouco inclinados, copas bem formadas e desenvolvidas, com diâmetro a $1,30 \mathrm{~m}$ do solo (DAP) entre 12 e $20 \mathrm{~cm}$. As amostras foram coletadas, sempre que possível, na face norte do tronco, utilizando-se formão e martelo para a retirada de um cubo com $15 \mathrm{~mm}$ de lado, da porção mais externa do xilema, a 1,30 m de altura.

Também foram amostradas duas árvores inclinadas em torno de $45^{\circ} \mathrm{em}$ relação ao solo, para investigar a ocorrência de lenho de reação, das quais foram tomadas uma amostra externa e outra interna em relação ao ângulo de inclinação, ambas a 1,30 m do solo. Foi ainda obtida uma amostra de raiz de uma das árvores, para verificar a ocorrência de amido neste órgão.

Preparo das amostras - As amostras foram submetidas à fervura com água, por cerca de três horas, e seccionadas em micrótomo de deslizamento. Foram obtidas secções histológicas de 18 a $22 \mu \mathrm{m}$ de espessura, submetidas à dupla coloração com solução aquosa de safranina (1\%) e de azul de astra (1\%), por 60 e 30 minutos, respectivamente (Burger \& Richter 1991). Após desidratadas em série etílica (30, 50, 70, 90, 95\% e álcool absoluto), as secções foram fixadas com Acetato de Butila e montadas em lâminas permanentes, empregando-se a resina sintética Entellan ${ }^{\circledR}$ (Kraus \& Arduin 1997).

Também foi preparado material dissociado, utilizando-se solução 1:1 de peróxido de hidrogênio $30 \%$ e ácido acético glacial, conforme metodologia descrita por Kraus \& Arduin (1997). O material foi submetido à coloração com solução aquosa de safranina (1\%), desidratado e montado em lâminas permanentes, da mesma forma descrita acima.

Para microscopia eletrônica de varredura, pequenos cubos de madeira foram seccionados, com cerca de $2 \mathrm{~mm}$ de lado, fixados em FAA 50 (formaldeído - ácido acético glacial - álcool etílico $50 \%$ ), desidratados em série etílica (Johansen 1940). O material foi levado ao ponto crítico no equipamento Balzers CPC 10. Posteriormente, as amostras foram aderidas a suportes metálicos com esmalte-grafite e submetidas à metalização com ouro no equipamento Balzers Sputtering SCD 030. Para a análise e registro eletromicrográfico foi utilizado MEV Jeol JSM-6360LV. Esses procedimentos foram realizados no Laboratório de Microscopia Eletrônica da Universidade Federal do Paraná (UFPR).

Análise das amostras - As análises foram realizadas sob microscópio óptico e eletrônico de varredura. As mensurações foram feitas em microscópio óptico, utilizando-se ocular com escala graduada. Também foi utilizada câmara clara acoplada ao microscópio para a contagem da freqüência de vasos e de raios, bem como para a ilustração de algumas características relevantes. As contagens e mensurações ( 30 repetições por árvore), bem como a descrição anatômica da madeira, foram realizadas conforme o proposto pela Associação Internacional dos Anatomistas de Madeira (IAWA 1989).

\section{Resultados e discussão}

Descrição anatômica - O xilema de $S$. commersoniana possui porosidade difusa, com eventual formação de anéis semi-porosos. Vasos solitários (42\%) e múltiplos de dois a seis, com arranjo radial (Fig. 1A), placas de perfuração simples, pontoações intervasculares e raio-vasculares areoladas coalescentes, circulares e alternas. Os vasos são pouco

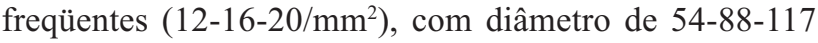
$\mu \mathrm{m}$ (lume); elementos de vaso com 164-602-1025 $\mu \mathrm{m}$ de comprimento, com ou sem apêndices (16-74-393 $\mu \mathrm{m}$ ) (Fig. 2). Eventualmente ocorrem vasos com conteúdos e tiloses.

As fibras são libriformes (Fig. 3B), com pontoações areoladas diminutas, com 656-1222-2050 $\mu \mathrm{m}$ de comprimento, 10-26-42 $\mu \mathrm{m}$ de largura, e paredes delgadas a espessas $(1,0-2,8-5,1 \mu \mathrm{m})$. São entesfreqüentes fibras com camada gelatinosa (Fig. 1I, Fig. 3C), preenchendo parcialmente ou completamente o lume, dispersas no lenho ou formando faixas no lenho inicial.

Ocorre parênquima axial apotraqueal difuso em agregados e paratraqueal escasso. O parênquima radial é unisseriado (bisseriado pouco freqüente) (Fig. 1B, C) com 3-15-52 células de altura $(164-805-2787 \mu \mathrm{m}), 12-22-35 \mu \mathrm{m}$ de largura, e freqüência linear de 18-20-26 raios $/ \mathrm{mm}$. Os raios são formados por camadas alternadas de células procumbentes, quadradas e eretas, eventualmente em agregados, com alternância de porções unisseriadas e bisseriadas (Fig. 3A). Células perfuradas de raio (Fig. 1F), com pontoações areoladas e placas de perfuração simples, circundadas por uma aréola bem evidente, são comuns nas camadas de células quadradas e eretas. Nestas camadas também ocorrem monocristais romboédricos de oxalato de cálcio, compartimentados em câmaras, e corpos de sílica (Fig. 1G).

Além dessas características, é muito comum a ocorrência de máculas, formadas por células parenquimáticas de formato irregular, com paredes lignificadas e contendo grãos de amido. Estes também ocorrem em grande quantidade nas células parenquimáticas radiais e axiais (Fig. 1H, I).

A maioria dos caracteres observados em S. commersoniana está de acordo com a descrição feita por Rodrigues (2005) para esta espécie e por Mennega (2005) para o gênero Sebastiania e diversos outros da subfamília Euphorbioideae.

$S$. commersoniana possui camadas de crescimento marcadas pelo achatamento das paredes das fibras e, em menor grau, pelo aumento na espessura das paredes dessas

6 Gleissolo: solo mineral, fortemente influenciado pelo lençol freático, em que a saturação hídrica plena leva ao processo de redução do ferro, em função de anoxia (EMBRAPA 1999).

7 Neossolo Flúvico: solo "novo", pouco evoluído, devido à reduzida atuação dos processos pedogenéticos, com ausência de horizonte B diagnóstico; derivado de sedimentos aluviais, com horizonte A assente sobre horizonte C constituído de camadas estratificadas, sem relação pedogenética entre si (EMBRAPA 1999).

8 Depósito Psamítico: depósito constituído por fração dominantemente arenosa, onde, além de não se observar qualquer evolução pedogenética entre as camadas e lentes, não é evidenciada a presença de horizonte A, explicitando deposição recente (Curcio 2006). 

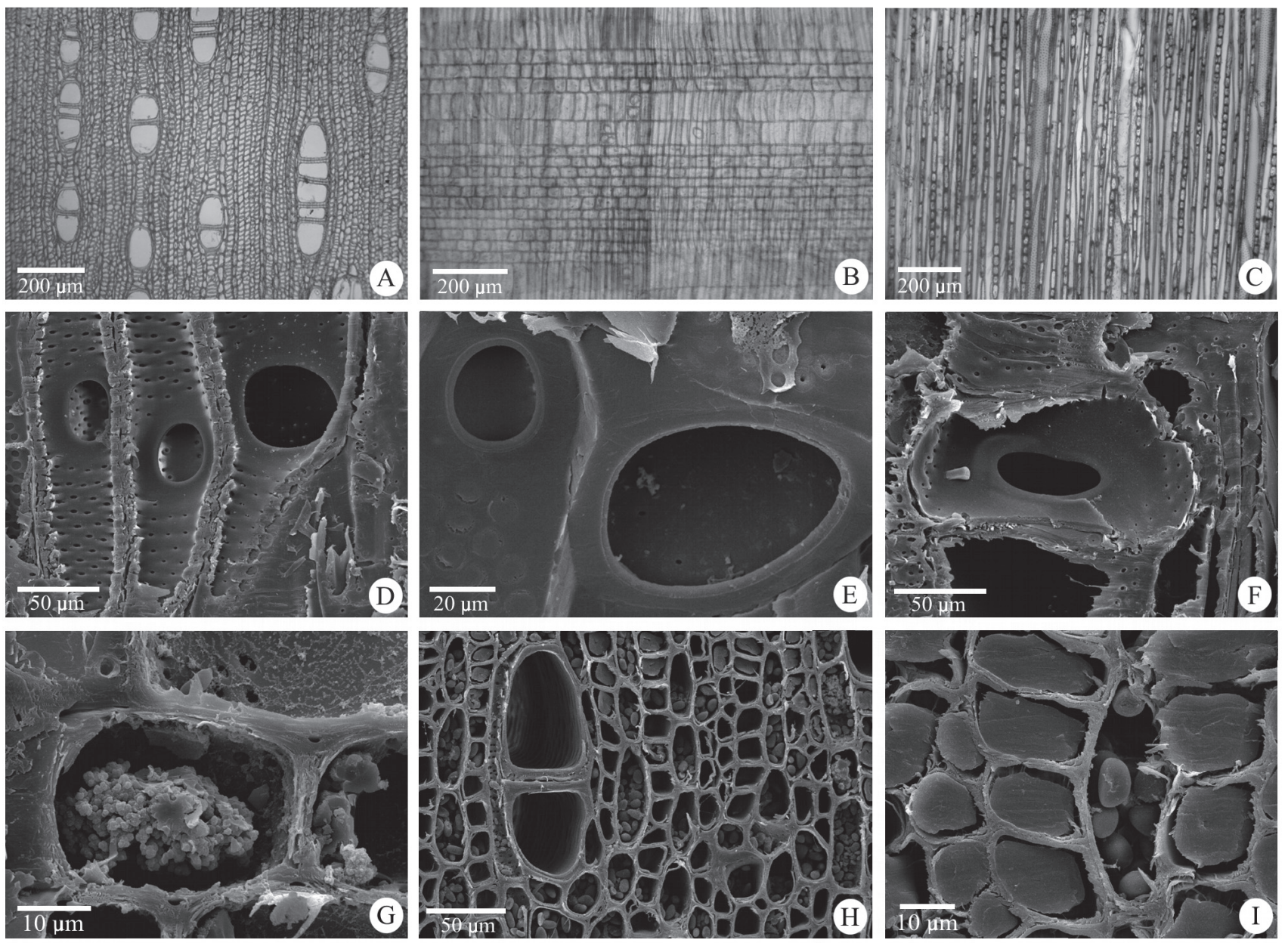

Figura 1. Xilema secundário de Sebastiania commersoniana (Baillon) Smith \& Downs (Euphorbiaceae). A: plano transversal; B: plano radial; C: plano tangencial; D, E: elementos de vaso com placas de perfuração simples; F: célula perfurada de raio; G: corpo de sílica em célula de raio; H: vasos em plano transversal, presença de fibras com camada gelatinosa, grãos de amido em células parenquimáticas; I: fibras com camada gelatinosa preenchendo completamente o lume.

células no lenho tardio. Tais características coincidem com a tendência de diversas espécies de Euphorbiaceae (Mennega 2005), tal como ocorre em Alchornea triplinervea e A. sidifolia, em solos sujeitos à inundação (Callado et al. 2001), e em Croton urucurana, em solo bem drenado (Luchi 2004).

Os aspectos qualitativos mais relevantes da estrutura anatômica do lenho de $S$. commersoniana são discutidos a seguir, em termos funcionais. Para uma discussão detalhada dos aspectos quantitativos da anatomia do xilema dessa espécie, relacionados à condição ambiental, ver Cosmo (2008).

Células perfuradas de raio - Esta é uma característica muito freqüente em Euphorbiaceae (Mennega 2005) e foi observada em todas as árvores de S. commersoniana avaliadas. Essas células são mais facilmente visualizadas no plano radial, conectando tangencialmente dois vasos e/ou conectando-se a outras células de mesma natureza, por placas de perfuração simples circundadas por uma aréola bem evidente. Além disso, também se comunicam com as demais células de raio, de parênquima axial, e com elementos de vaso, através de pontoações areoladas (Fig. 4).
As células perfuradas ocorrem tanto nas camadas de células quadradas, quanto nas de células eretas, e sua origem nas iniciais radiais é bastante clara, considerando sua disposição em relação ao conjunto de células que compõem o raio (Fig. 5).

Este tipo de célula tem sido descrita por diversos autores, para vários táxons. Botosso \& Gomes (1982) observaram séries de células perfuradas de raio e de conexões radias curtas entre dois segmentos de vaso (denominadas pelos autores como vasos radiais) em Annonaceae. Ceccantini \& Angyalossy-Afonso (2000) observaram-nas em Bathysa meridionalis, nas camadas de células quadradas e eretas. Ocorrem ainda em Tabebuia cassinoides (Kuniyoshi 1993) e em Casearia sylvestris (Ceccantini 1996). Joffily et al. (2007) relatam a ocorrência de células perfuradas de raio em nove espécies de Maytenus, presentes inclusive na raiz de M. brasiliensis e M. obtusifolia, e sugerem que esta característica tenha valor taxonômico para o gênero. Terrazas (2000) analisou células perfuradas de raio em Cactáceas (Pachycereeae), e Merev et al. (2005) observaram-nas em diversas espécies ocorrentes na Turquia. A primeira menção 

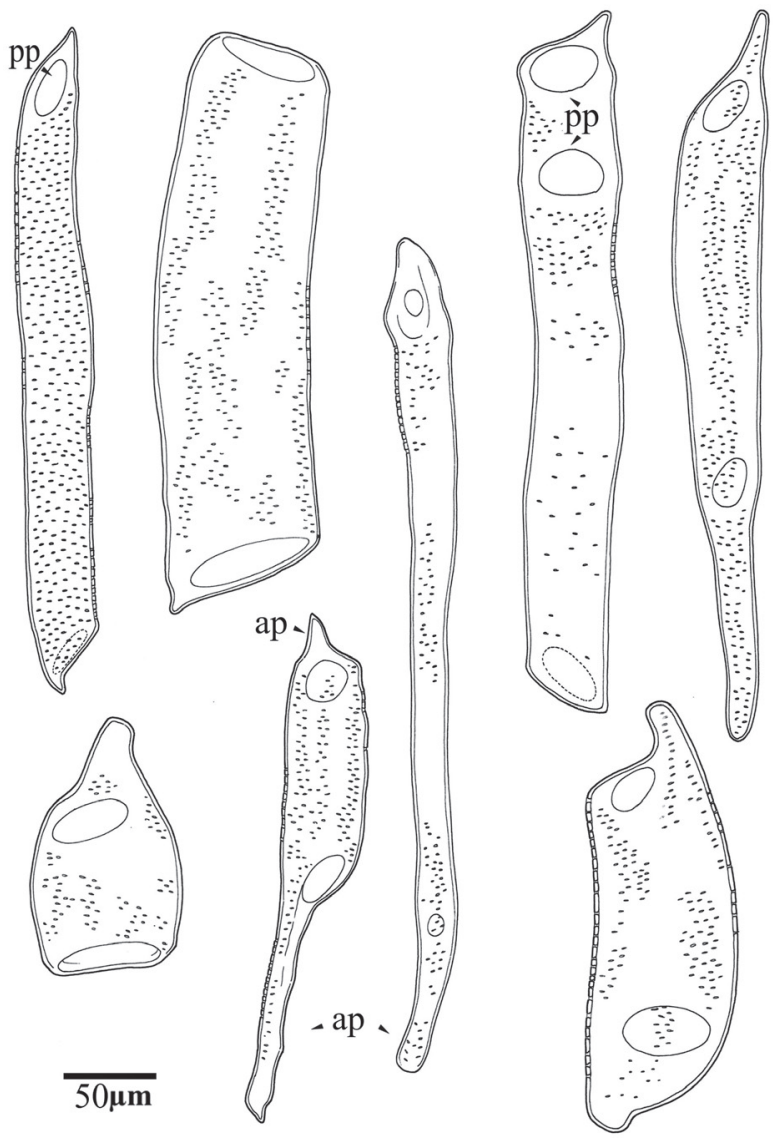

Figura 2. Elementos de vaso do lenho de Sebastiania commersoniana (Baillon) Smith \& Downs (Euphorbiaceae). Ilustração: N. L. Cosmo.

a este tipo de célula em Melastomataceae foi feita recentemente por Marcon-Ferreira et al. (2009).

Devido à carência de dados na literatura sobre as implicações fisiológicas desse tipo de célula, torna-se difícil interpretar sua influência em termos funcionais. Porém, algumas hipóteses podem ser levantadas com base nos fatores que implicam em maior ou menor capacidade de condução.

A presença das células perfuradas de raio deve representar um incremento no transporte da água no sentido tangencial e propiciar maior interação entre vasos e raios. Além disso, se cada vaso possuir pelo menos duas células perfuradas de raios ao longo de seu comprimento, conectando-o com outros dois vasos, forma-se um sistema virtualmente contínuo de vasos ao longo do xilema, conectados por células perfuradas de raio. Isto certamente representa aumento na eficiência condutiva, uma vez que a água passaria livremente de um vaso a outro pelas placas de perfuração das células de raio.

Ceccantini \& Angyalossy-Afonso (2000) observaram que as placas de perfuração das células perfuradas de raio de Bathysa meridionalis são maiores que as dos elementos
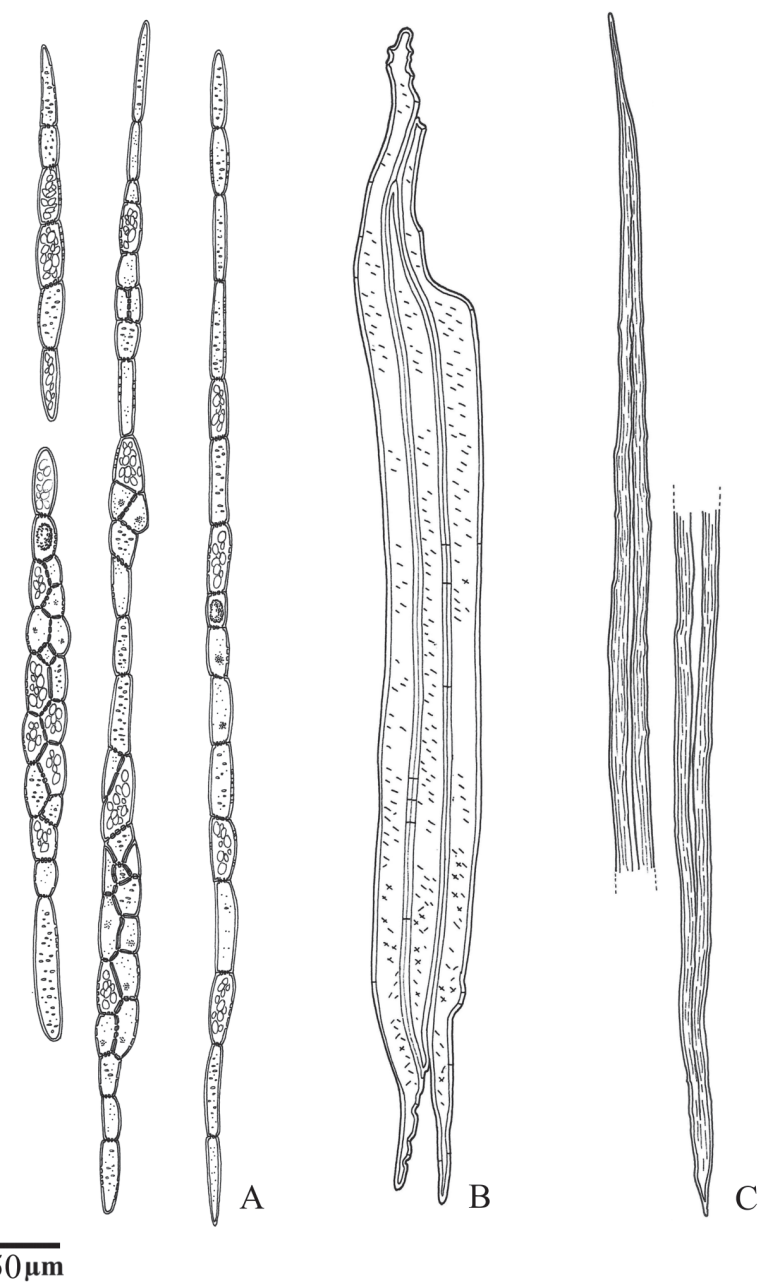

Figura 3. Parênquima radial (A) e fibras (B: fibras libriformes; C: Fibra gelatinosa) do lenho de Sebastiania commersoniana (Baillon) Smith \& Downs (Euphorbiaceae). Ilustração: N. L. Cosmo.

de vaso, sugerindo que essas propiciam maior condutividade hidráulica quando comparadas às placas de perfuração dos vasos. Porém, a largura das células perfuradas é menor que a dos vasos, representando maior resistência ao fluxo. Os autores não fazem referência às possíveis implicações dessas células na segurança do sistema condutivo, destacando a necessidade de estabelecer o papel das células perfuradas de raio, em termos funcionais.

Máculas - As máculas no lenho de S. commersoniana são freqüentes, constituídas de células parenquimáticas com forma irregular e paredes de espessura bastante variável (Fig. 6; Fig. 7A-C). Rodrigues (2005) também constatou a ocorrência de máculas nessa espécie, destacando a grande quantidade de amido, a presença de compostos fenólicos, e a maior lignificação das paredes das células, tanto nas máculas, quanto em sua periferia. Máculas são formadas em resposta a injúrias ao câmbio, causadas por danos bióticos ou abióticos. Tais estruturas são muito freqüentes em espécies de ambientes fluviais, dadas as suas condições adversas (Schweingruber 1996). 

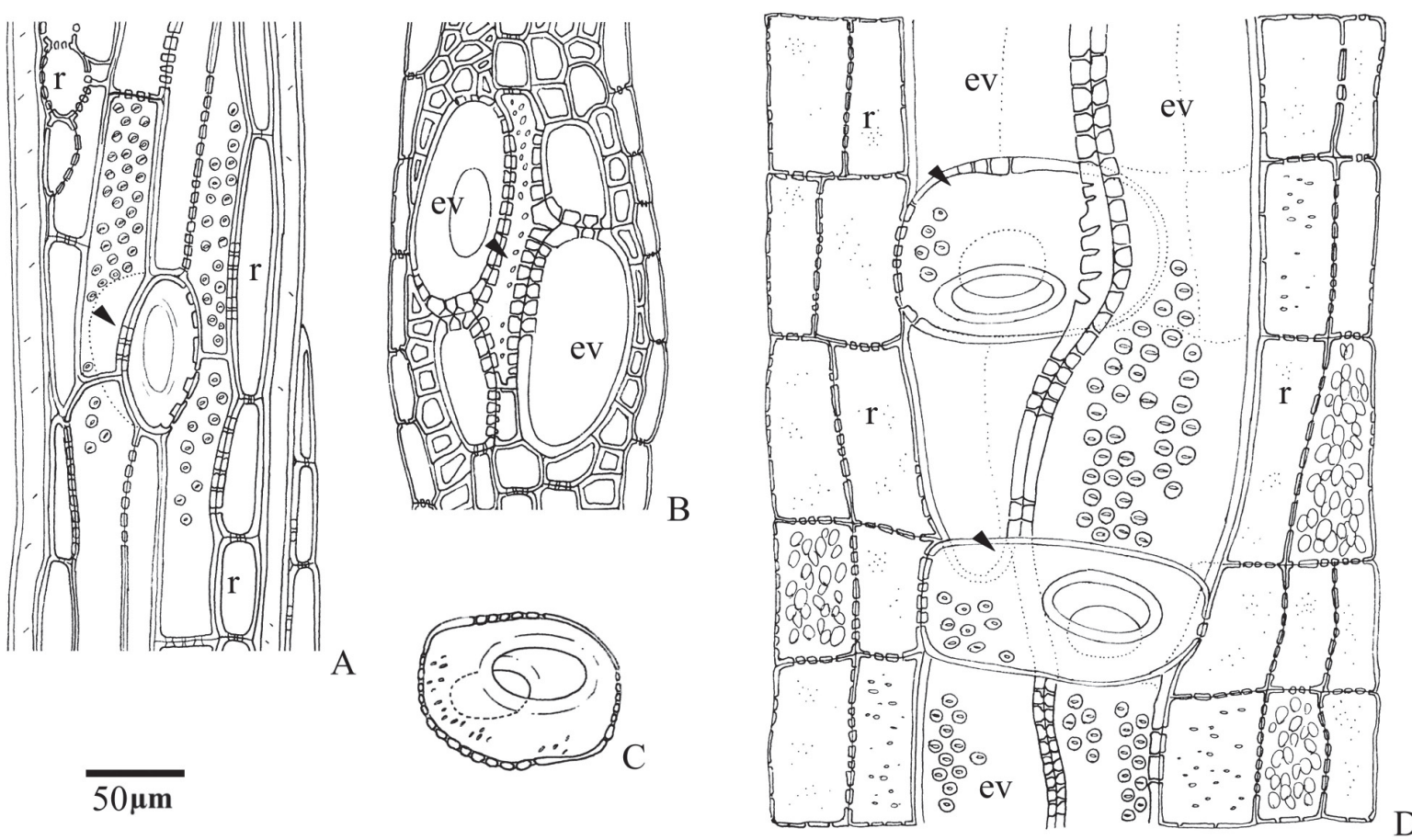

Figura 4. Células perfuradas de raio no lenho de Sebastiania commersoniana (Baillon) Smith \& Downs (Euphorbiaceae). A: plano tangencial; B: plano transversal; C: célula isolada; D: plano radial. Ilustração: N. L. Cosmo.

A natureza longeva do caule nas árvores implica na necessidade de inúmeros mecanismos de segurança, essenciais para a manutenção de suas funções. Dentre eles estão: a capacidade de prevenção de danos, a habilidade de regeneração e mecanismos de compartimentação de injúrias (Hinckley \& Schulte 1995). Em geral, as árvores têm uma capacidade marcante de regenerar partes danificadas. Sua potencialidade inerente pode ser verificada na habilidade de proliferar células parenquimáticas em vários tecidos secundários, especialmente a partir da zona cambial e de suas células derivativas imediatas (Brown 1974).

Embora a origem do tecido de cicatrização possa variar consideravelmente, na maioria das espécies lenhosas os raios são os principais responsáveis por esse processo (Kozlowski 1962). Essa tendência é observada em $S$. commersoniana, uma vez que as células de raio parecem contribuir em grande parte, se não totalmente, para a formação das máculas (Fig. 7B, C).

$\mathrm{Na}$ espécie estudada, as máculas geralmente ocorrem mais próximas ao lenho tardio. Isto pode indicar que a causa mais comum das injúrias ocorra no período final de crescimento. Ceccantini (1996) observou a mesma tendência em máculas de Casearia sylvestris, muito semelhantes em sua morfologia às de $S$. commersoniana. Este autor associa a presença desta característica à ocorrência de geadas, evento comum também na região do presente estudo. Outras possíveis explicações para a origem das máculas em S. commersoniana seriam os efeitos da saturação hídrica prolongada ou mesmo de déficit hídrico. Nos dois casos, a deficiência na absorção de água pelas raízes poderia ocasionar injúrias em determinados pontos da região cambial.
Tiloses, vasos com conteúdo e canal traumático - Em apenas uma das amostras foi observada a ocorrência de um canal traumático, indicando a pequena freqüência dessa característica nas árvores estudadas. Mais comum, no entanto, é a presença de conteúdos densos e tiloses em vasos, especialmente naqueles próximos às máculas, sugerindo que os mesmos fatores estão levando à formação dessas características.

Tilose é o crescimento de células parenquimáticas para o interior do lume de vasos através das pontoações, ocorrendo em elementos que sofreram cavitação (Cutter 1971). Em diversas espécies é comum a formação de tiloses em vasos da periferia de lesões, representando um isolamento efetivo dos tecidos vivos contra injúrias e infecções. Dentre outros mecanismos de isolamento, podem ocorrer impregnações de conteúdos no lume dos vasos e processos de lignificação da parede de células do xilema que tenham sofrido injúria (Zimmermann 1983). Todas estas características foram observadas no lenho de $S$. commersoniana.

Amido - Em todas as amostras analisadas foi observada grande quantidade de grãos de amido nas células parenquimáticas radiais, em especial no parênquima axial, onde praticamente ocupam todo o interior da célula.

O caule de espécies lenhosas em muitos casos funciona como estoque de uma série de substâncias de reserva de longo ou curto prazo. As células de parênquima radial e axial são os principais locais de estocagem, que depende da proporção do volume que estas células representam, em oposição aos outros tipos de tecido (Pate \& Jeschke 1995). É provável que o amido estocado em $S$. commersoniana 

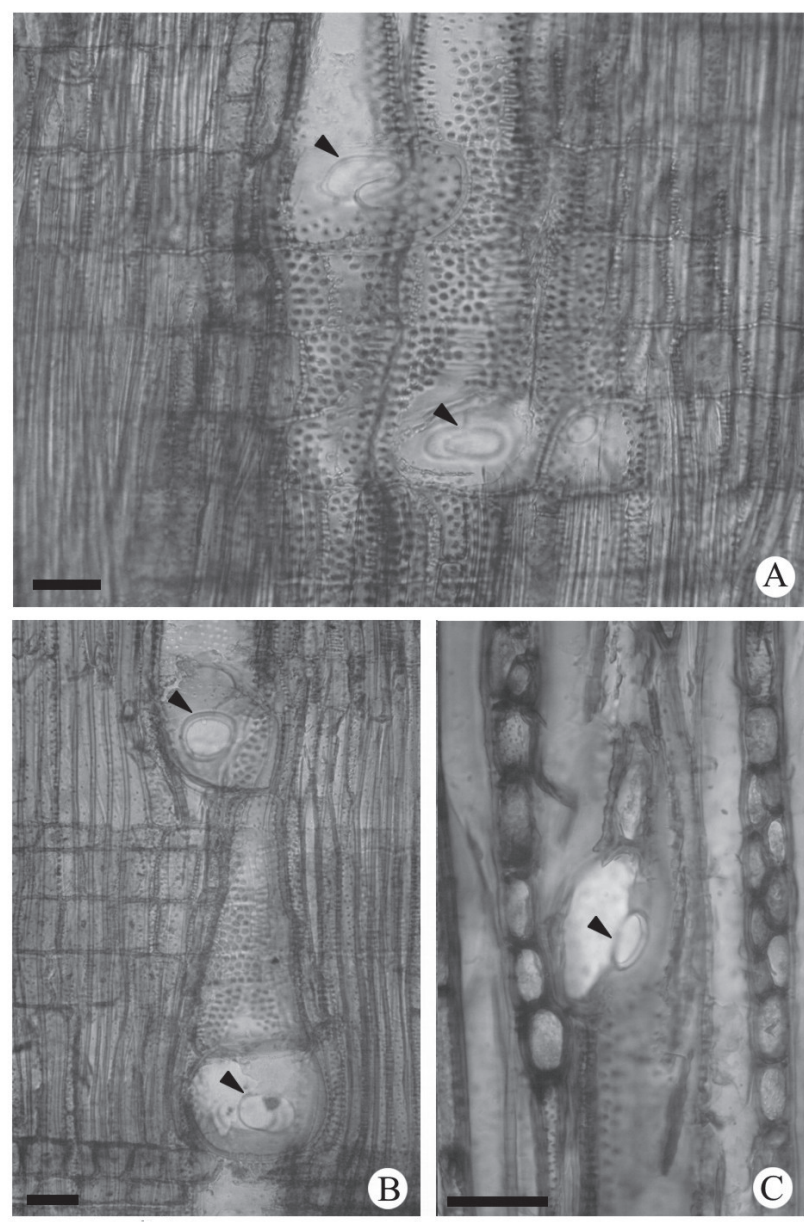

Figura 5. Células perfuradas de raio no lenho de Sebastiania commersoniana (Baillon) Smith \& Downs (Euphorbiaceae). As setas indicam a presença de aréola ao redor das placas de perfuração (escalas: $50 \mu \mathrm{m}$ ).

seja de grande valor no período de retomada de crescimento após o inverno, uma vez que nessa época são emitidas as novas folhas, juntamente com as inflorescências. Além disso, a espécie normalmente produz grande quantidade de frutos e sementes, sendo comum, inclusive, ocorrer redução na quantidade de folhas durante a maturação dos mesmos.

Os carboidratos no xilema estão intimamente relacionados à atividade cambial, especialmente no início da estação de crescimento (Wilcox 1962), e ao desenvolvimento das fases fenológicas (Ziegler 1964). A ocorrência de amido no xilema, no entanto, não indica apenas reserva. Segundo Carlquist (2001), outras implicações da presença dessa substância no xilema têm sido investigadas, como, por exemplo, por Braun (1984).

De acordo Braun (1984), nos tecidos acessórios (células de parênquima radial e/ou axial, diretamente associadas aos vasos) de árvores decíduas de clima temperado, o amido estocado é quebrado durante a fase de mobilização, no início da primavera. Este processo libera substâncias osmoticamente ativas nos vasos do xilema, gerando alta pressão osmótica e, consequentemente, absorção e transporte de água sob pressão positiva. Por outro lado, em espécies tropicais, sujeitas à condição de alta umidade, a absorção osmótica de água deve ser um princípio essencial de transporte, que funciona constantemente, alternando com a transpiração.

Essa pressão pode operar em direção ao ápice da planta, graças ao processo de gutação, em que as folhas funcionam passivamente como válvulas, apresentando ou não hidatódios. A produção de amido neste processo, segundo o autor, poderia ser uma forma de "tirar de circulação" o excedente de açúcares produzidos - uma vez que se trata de uma substância osmoticamente inativa - não representando, necessariamente, uma reserva energética (Braun 1984).

Em S. commersoniana, a presença de grande quantidade de amido nas raízes permite à espécie manter altos níveis de metabolismo anaeróbico, em situações de inundação, como observado em plântulas submetidas à saturação hídrica (Lobo \& Joly 1998). Analisando uma amostra de raiz de $S$. commersoniana, foi possível confirmar que ocorre grande quantidade de amido neste órgão também em plantas adultas.

É provável, portanto, que o grande estoque de amido em S. commersoniana esteja relacionado tanto aos processos fenológicos, quanto ao crescimento da árvore. Deve-se também considerar a possibilidade do amido estar envolvido no transporte de água e nutrientes e nos processos metabólicos que permitem à espécie tolerar períodos de inundação.

Estudos mais detalhados poderiam determinar quais as funções principais do amido no xilema desta espécie e suas implicações fisiológicas, bem como, a partir de análises quantitativas, investigar possíveis variações sazonais deste componente. Fibras gelatinosas - As fibras gelatinosas no lenho de $S$. commersoniana são facilmente identificáveis no material submetido à dupla coloração, destacando-se a coloração azul brilhante da camada gelatinosa. Tais células ocorrem tanto dispersas entre as fibras normais, quanto concentradas em pequenos grupos, ou, como observado em algumas amostras, formando faixas contínuas no lenho inicial.

Estas células possuem uma camada interna espessa de parede celular constituída de celulose altamente cristalina (camada gelatinosa $\mathrm{S}(\mathrm{G})$ ), na qual a orientação das microfibrilas é aproximadamente paralela ao eixo da fibra (Du \& Yamamoto 2007). No caso de $S$. commersoniana, ocorrem fibras gelatinosas com camada $\mathrm{S}(\mathrm{G})$ convoluta ou normal, com freqüência preenchendo todo o lume.

Mennega (2005) observou esse tipo de fibra em muitos gêneros de Euphorbiaceae, inclusive em Sebastiania (S. brasiliensis e $S$. argutidens), cuja camada gelatinosa preenche parcialmente ou por completo o lume. Callado et al. (2001) constataram a ocorrência de fibras gelatinosas em duas outras espécies dessa família (Alchornea triplinervea e A. sidifolia), observando que, em solo periodicamente inundado, este tipo de fibra forma faixas no lenho inicial, enquanto que, em solos permanentemente inundados, formam-se zonas irregulares de fibras gelatinosas no anel de crescimento. Em Croton urucurana, Luchi (2004) observou a presença de camada gelatinosa apenas nas fibras de amostras provenientes de solo bem drenado, quando comparado às áreas úmidas e inundadas. 

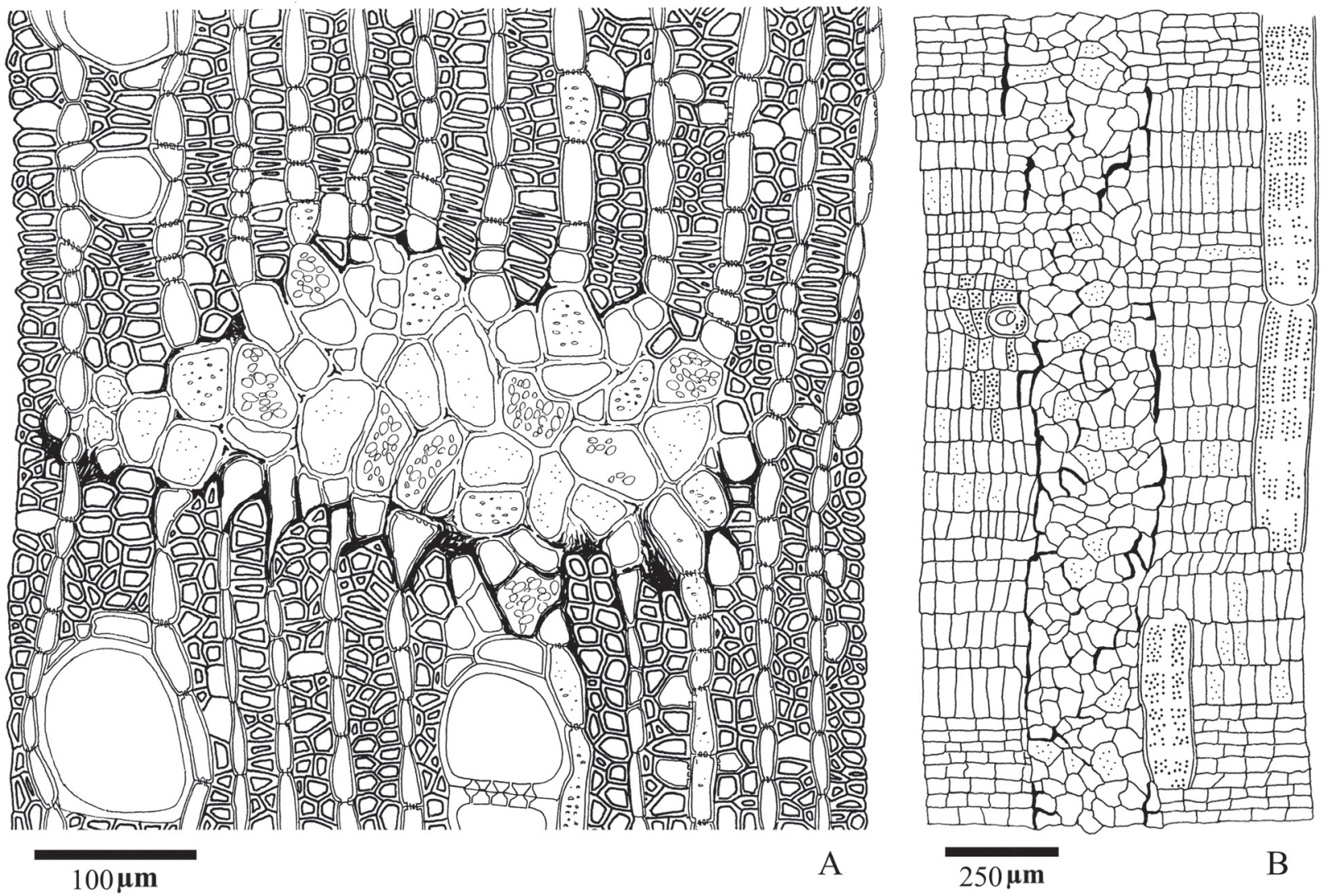

Figura 6. Máculas no lenho de Sebastiania commersoniana (Baillon) Smith \& Downs (Euphorbiaceae). A: plano transversal; B: plano radial. Ilustração: N. L. Cosmo.

Nas amostras de $S$. commersoniana, porém, não foi observada uma relação clara entre a distribuição das fibras gelatinosas e os diferentes tipos de solo dos locais de coleta. Se tal relação existe, provavelmente poderia ser detectada amostrando-se condições pedológicas ainda mais contrastantes em termos hídricos.

Lenho de Reação - Embora possa haver influência do regime hídrico sobre a formação das fibras gelatinosas, estas são típicas de lenho de tensão das angiospermas dicotiledôneas arbóreas, desenvolvido na parte superior de um tronco inclinado (Cutter 1971). Os primeiros pesquisadores a investigarem a formação do lenho de reação em angiospermas acreditavam que este resultava do estresse de tensão na parte superior de galhos e de troncos inclinados, daí a adoção do termo "lenho de tensão" (Wardrop 1964; Cutter 1971; Brown 1974). Pesquisas posteriores, no entanto, indicaram que o principal fator responsável pela formação de lenho de reação é a gravidade (Wardrop 1964). Segundo Brown (1974), o mecanismo fisiológico que explica a formação do lenho de reação é de natureza hormonal e está diretamente relacionado à quantidade relativa ou ao balanço de auxina entre a parte superior e inferior do caule. A gravidade, de alguma forma, afeta a distribuição de auxina causando um maior acúmulo no lado inferior de galhos ou troncos inclinados, promovendo a formação de lenho de compressão em gimnospermas e de tensão em angiospermas.
Observando amostras coletadas de duas árvores inclinadas, notou-se que, em contraste com as amostras coletadas na face inferior do tronco (lado interno ao ângulo de inclinação) - que possuem poucas fibras gelatinosas, com camadas $\mathrm{S}(\mathrm{G})$ pouco expressivas - nas amostras coletadas no lado externo à inclinação, as fibras gelatinosas são muito abundantes. Nestas, a camada $S(G)$ é bastante evidente, estando presente inclusive nas últimas camadas de fibras do lenho tardio, diferente do que se observou nas demais amostras. Estes resultados sugerem que ocorre formação de lenho de tensão em $S$. commersoniana e que uma de suas características é a formação mais intensa de fibras gelatinosas.

Analisando amostras coletadas para análise de crescimento do tronco, provenientes das mesmas árvores aqui avaliadas, Cosmo (2008) observou correspondência entre camadas de crescimento com expressiva quantidade de fibras gelatinosas (evidentes pela coloração pouco mais escura que o normal) e a inclinação do tronco, uma vez que são mais freqüentes no lado externo à inclinação das árvores. Notou-se também, no material analisado, que a ocorrência de lenho de tensão está frequentemente associada ao crescimento excêntrico do tronco, tal como ocorre em grande número de espécies, de acordo com Wardrop (1964).

Por outro lado, as amostras com fibras gelatinosas em faixas estreitas no lenho inicial, ou dispersas no xilema, não indicam necessariamente a presença de lenho de reação, 


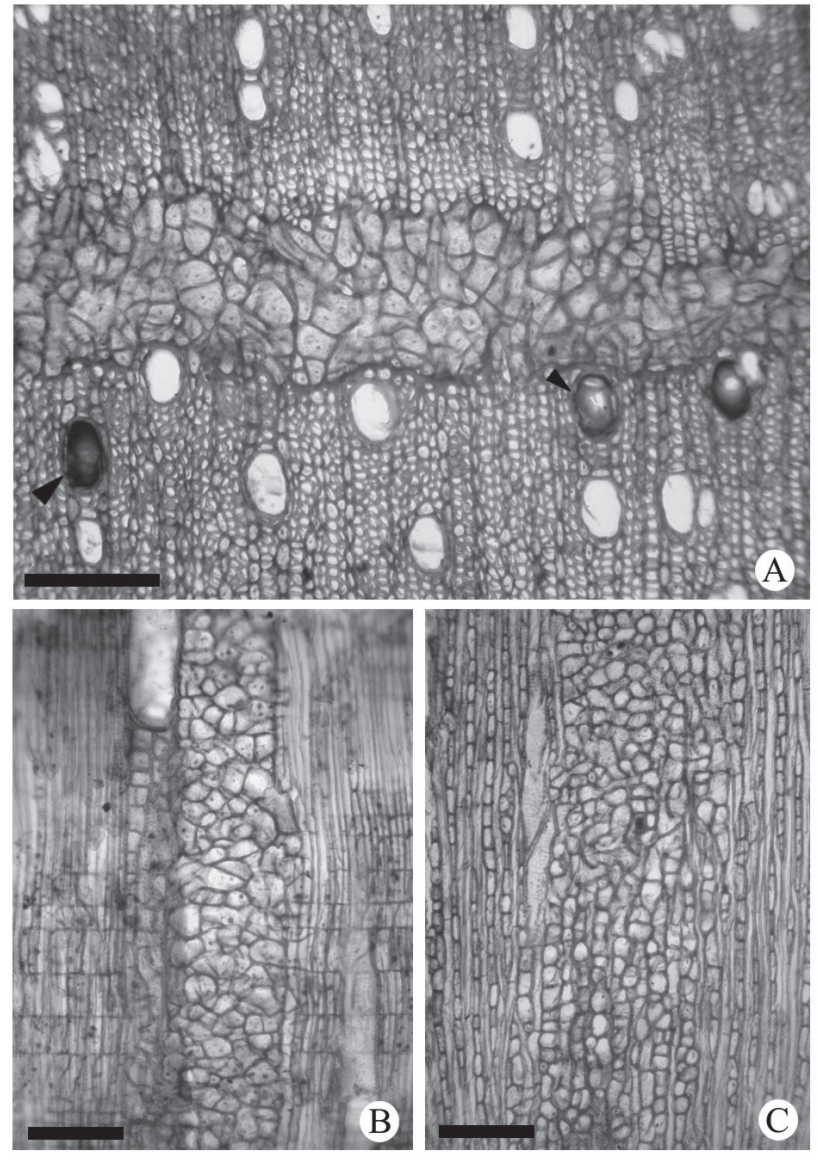

Figura 7. Máculas no lenho de Sebastiania commersoniana (Baillon) Smith \& Downs (Euphorbiaceae). A: plano transversal; B: plano radial; C: plano tangencial. As setas apontam para vasos com conteúdo na periferia das máculas (escalas: $200 \mu \mathrm{m}$ ).

uma vez que essa é uma característica muito comum em Euphorbiaceae que, de acordo com Mennega (2005), não tem necessariamente correlação com a curvatura ou inclinação do tronco nessa família.

O lenho de reação é formado em resposta a orientações não ótimas do tronco ou galhos de modo a manter estáveis os padrões estruturais. A alteração que resulta da formação do lenho de reação deve ser interpretada como uma quebra de equilíbrio, e o lenho de reação é formado no lado que irá servir para restabelecer a posição de equilíbrio (Du \& Yamamoto 2007).

O desenvolvimento do lenho de reação em $S$. commersoniana pode ser entendido como uma importante resposta da espécie às diversas variações ambientais a que está sujeita nos ambientes dinâmicos das planícies fluviais, especialmente quanto à instabilidade pedológica, conjugada à ocorrência de períodos de cheias, a danos nas raízes e na copa e aos processos de deposição de sedimentos.

Observando as árvores de $S$. commersoniana em campo, nota-se que a espécie normalmente não desenvolve inflexão acentuada do tronco como resposta à inclinação, diferentemente do que ocorre com outras espécies da planície fluvial, tais como Luehea divaricata e Schinus terebintifo- lius. Quando tem seu tronco significativamente inclinado, a espécie responde com a emissão de galhos epicórmicos como estratégia de sobrevivência, enquanto o tronco principal se mantém relativamente retilíneo. Seria interessante investigar, em trabalhos futuros, possíveis implicações do lenho de reação neste processo, bem como o valor adaptativo desta característica em $S$. commersoniana, considerando as condições limitantes dos ambientes em que a espécie ocorre.

Outra abordagem relevante é a identificação de possíveis variações quantitativas na estrutura anatômica da madeira, associadas à formação do lenho de tensão, uma vez que a anatomia do lenho nessa condição pode variar não somente pela presença das fibras gelatinosas, mas também quanto às dimensões dos elementos anatômicos. De acordo com Wardrop (1964), a extensão em que a estrutura anatômica é modificada em lenhos de reação de caules e galhos é extremamente variável. Portanto, são necessários estudos mais detalhados com $S$. commersoniana para que possíveis alterações na estrutura do xilema em lenho de tensão sejam avaliadas.

\section{Referências bibliográficas}

Barddal, M.L.; Protil, C.Z.; Souza, S.G.A. de. 2003. Fitossociologia do componente arbóreo de um trecho da planície do rio Iraizinho, Piraquara, Paraná, Brasil. Revista Estudos de Biologia 25: 17-28.

Barddal, M.L. 2006. A influência da saturação hídrica na distribuição de oito espécies arbóreas da Floresta Ombrófila Mista Aluvial do rio Iguaçu, Paraná, Brasil. Curitiba, UFPR.

Botosso, P.C. \& Gomes, A.V. 1982. Radial vessels and series of perforated ray cells in Annonaceae. IAWA Bulletin 3: 103-182.

Braun, H.J. 1984. The significance of the accessory tissues of the hidrosystem for osmotic water shifting as the second principle of water ascent, with some thoughts concerning the evolution of trees. IAWA Bulletin 5: 275-294.

Brown, C.L. 1974. Secundary growth. pp. 67-123. In: M.H. Zimmermann $\&$ C.L. Brown (eds.). Trees structure and function. New York, Spring-Verlag.

Burger, L.M. \& Richter, H.G. 1991. Anatomia da madeira. São Paulo, Nobel.

Callado, C.H.; Neto, S.J. da S.; Scarano, F.R.; Barros, C.E.; Costa, C.G. 2001. Anatomical features of growth rings in flood-prone trees of the Atlantic Rain Forest in Rio de Janeiro, Brazil. IAWA Journal 22: 29-42.

Carlquist, S. 2001. Comparative wood anatomy: systematic, ecological, and evolutionary aspects of dicotyledon wood. New York, SpringVerlag.

Ceccantini, G. \& Angyalossy-Afonso, V. 2000. Perforated ray cells in Bathysa meridionalis (Rubiaceae). IAWA Journal 21: 77-82.

Ceccantini, G. 1996. Anatomia ecológica do lenho de espécies de cerrado e mata: Casearia sylvestris Sw. e Machaerium villosum Vog. São Paulo, Universidade de São Paulo.

Cosmo, N.L. 2008. Anatomia ecológica e crescimento do lenho de Sebastiania commersoniana (Baillon) Smith \& Downs, em diferentes condições geomorfológicas e pedológicas da planície do rio Iguaçu-PR. Curitiba, UFPR.

Curcio, G.R. 2006. Relações entre geologia, geomorfologia, pedologia e fitossociologia nas planícies fluviais do rio Iguaçu, Paraná, Brasil. Curitiba, UFPR.

Curcio, G.R.; Galvão, F.; Bonnet, A.; Barddal, M.L.; Dedecek, R.A. 2007. A floresta fluvial em dois compartimentos do rio Iguaçu, Paraná, Brasil. Floresta 37: 125-146.

Cutter, E.G. 1971. Plant anatomy: experiment and interpretation. Reading, Addison-Wesley Publishing Company. 
Du, S. \& Yamamoto, F. 2007. An overview of biology of reaction wood formation. Journal of Integrative Plant Biology 49: 131-143.

Hinckley, T.M. \& Schulte, P.J. 1995. Stems in de biology of the tissue, organism, stand, and ecosystem. pp. 409-428. In: Gartner, B.L. Plant stems: physiology and functional morphology. San Diego, Academic Press.

IAWA. 1989. International Association of Wood Anatomists. IAWA list of microscopic features for hardwood identification. IAWA Committee.

Isernhagen, I. 2001. A fitossociologia florestal no Paraná e os programas de recuperação de áreas degradadas: uma avaliação. Curitiba, UFPR.

Joffily, A.; Domingues, D.F.; Vieira, R.C. 2007. Perforated ray cells in the root and stem of Maytenus (Celastroideae-Celastraceae) IAWA Journal 28(3): 311-314.

Kolb, R.M.; Medri, M.E.; Bianchini, E.; Pimenta, J.A.; Giloni P.C., Correa G.T. 1998. Anatomia ecológica de Sebastiania commersoniana (Baillon) Smith \& Downs (Euphorbiaceae) submetida ao alagamento. Revista Brasileira de Botânica 21: 305-312.

Kozlowski, T.T. 1962. Photosynthesis, climate, and tree growth. Pp.149163. In: Kozlowski, T.T. Tree growth. New York, The Ronald Press Company.

Kuniyoshi, Y.S. 1993. Aspectos morfo-anatômicos do caule, raiz e folha de Tabebuia cassinoides (Lam.) DC (Bignoniaceae) em diferentes fases sucessionais no litoral do Paraná. Curitiba, UFPR.

Kraus, J.E. \& Arduin, M. 1997. Manual básico de métodos em morfologia vegetal. Rio de Janeiro, EDUR.

Lobo, P.C. \& Joly, C.A. 1998. Tolerance to hypoxia and anoxia in neotropical tree species. Pp.137-156. In: F.R. Scarano \& A.C. Franco (eds.). Ecophysiological strategies of xerophytic and anphibious plants in the neotropics. Series Oecologia Brasiliensis v.IV.

Lobo, P.C. \& Joly, C.A. 2000. Aspectos ecofisiológicos da vegetação de mata ciliar do sudeste do Brasil. Pp. 143-157. In: Rodrigues, R.R. \& Leitão-Filho, H.F. (eds.). Matas ciliares: conservação e recuperação. São Paulo, Edusp/Fapesp.

Lorenzi, H. 1992. Árvores brasileiras: manual de identificação e cultivo de plantas arbóreas nativas do Brasil. Nova Odessa, Plantarum.

Luchi, A.E. 2004. Anatomia do lenho de Croton urucurana Baill. (Euphorbiaceae) de solos com diferentes níveis de umidade. Revista Brasileira de Botânica 27: 271-280.
Maack, R. 1968. Geografia Física do Estado do Paraná. Curitiba, BADEP/UFPR/IBPT.

Mennega, A.M.W. 2005. Wood anatomy of the subfamily Euphrbioideae: a comparison with subfamilies Crotonoideae and Acalyphoideae and the implications for circumscription of the Euphorbiaceae. IAWA Journal 26: 1-68.

Marcon-Ferreira, M.L.; Barros, C.F.; Costa, C.G. 2009. Perforated ray cells in Miconia ternatifolia - A first report for the family Melastomataceae. IAWA Journal. 30: 163-164.

Merev, N.; Gerçek, Z.; Serdar, B. 2005. Wood anatomy of some turkish plants with special reference to perforated ray cells. Turkish Journal of Botany 29: 269-281.

Pate, S.P. \& Jeschke, W.D. 1995. Role of stems in transport, storage, and circulation of ions and metabolites by the whole plante. Pp.177204. In: Gartner, B.L. (ed.). Plant stems: physiology and functional morphology. San Diego, Academic Press.

Reitz, R.; Klein, R.M.; Reis, A. 1983. Projeto madeira do Rio Grande do Sul. Itajaí: H.B.R., SUDESUL, DRNR.

Rodrigues, T.T. 2005. Os efeitos do solo contaminado com petróleo na estrutura anatômica e estado nutricional do lenho jovem de Campomanesia xanthocarpa Berg (Myrtaceae) e Sebastiania commersoniana (Baillon) Smith \& Downs (Euphorbiaceae). Curitiba, UFPR.

Schweingruber, F.H. 1996. Tree rings and environment dendroecology. Birmensdorf, Swiss Federal Institute for Forest, Snow and Landscape Research. Berne, Stuttgart, Viena, Haupt.

Terrazas, T. 2000. Occurrence of perforated ray cells in genera of Pachyceraceae (Cactaceae) IAWA Journal 21(4): 457-462.

Wardrop, A.B. 1964. The reaction anatomy of arborescent angiosperms. pp. 405-456. In: Zimmermann, M.H. (ed.). The formation of wood in forest trees. New York, Academic Press.

Wilcox, H. 1962. Cambial growth characteristics. Pp. 57-88. In: Kozlowski, T.T. (ed.). Tree growth. New York, The Ronald Press Company.

Ziegler, H. 1964. Storage, mobilization and distribution of reserve material in trees. Pp. 303-320. In: Zimmermann, M.H. (ed.). The formation of wood in forest trees. New York, Academic Press.

Zimmermann, M.H. 1983. Xylem structure and the ascent of sap. Berlin, Springer-Verlag.

Versão eletrônica do artigo em www.scielo.br/abb e http://www.botanica.org.br/acta/ojs 